Please quote as: Leimeister, J. M.; Sidiras, P. \& Krcmar, H. (2004): Success factors of virtual communities from the perspective of members and operators - An empirical study. In: Proceedings of the Hawai'i International Conference on System Sciences (HICSS 37), Big Island, Hawaii. 


\section{Success factors of virtual communities from the perspective of members and operators: An empirical study}

\author{
Jan Marco Leimeister, Pascal Sidiras \\ Information Systems Department \\ Hohenheim University \\ Germany
}

\begin{abstract}
:
Virtual communities have been the focus of research for some time. However, while many studies provide recommendations on how to build, extend and manage virtual communities, few verify the success factors they consider essential for virtual communities. Conclusions made regarding basic preferences and distinct priorities of different stakeholders in virtual communities have not been empirically substantiated. This study uses an online survey of members and operators of virtual communities to evaluate success factors discussed in the literature. Incongruences between members and operators are identified and analysed. This research gains first empirically validated insights into success factors for establishing and managing virtual communities. The study results are summarised in ten hypotheses.
\end{abstract}

Key words: virtual community, success factors, onlinesurvey, hypotheses on how to build and manage virtual communities

\section{Introduction}

Virtual Communities ${ }^{1}$ have opened a broad field of research during the last years. Although numerous researchers have studied this research object [1-7], backgrounds, approaches and objectives of the studies differ significantly. The objective of this research is to evaluate success factors for virtual communities that have often been postulated in scientific literature and evaluate their practical importance from the perspective of members and operators of virtual communities. Based on this evaluation, deviations are identified and analysed. The results provide empirically validated insights into developing, introducing and managing virtual communities.

The paper is structured as follows: Section 2 provides operational definitions and an explanation on the background for the study. A set of success factors for virtual communities as found in literature and as identified by conducting expert interviews is presented. Section 3 describes the methodology used in this study. Details on data collection are provided in section 4 and

Synonymous to "Virtual Community" the term "Online Community" can be used.

\author{
Helmut Krcmar \\ Chair for Information Systems \\ Technical University of Munich \\ Germany
}

in section 5 the results of the data-analysis are presented. This paper concludes with a discussion of study results and an outlook on possible future research themes. A list of the success factors (divided by target groups and ranked by importance) is provided in the appendix of the paper.

\section{Definitions and Reference Frame- work}

\subsection{Virtual Communities}

For various reasons, no common agreement on the definition of the term ,virtual community“ could be identified in the literature [9]. First, virtual communities are a multidimensional research object which can be analysed from various perspectives including psychology, administrative science or computer science. The discipline initiating the study tends to define the term virtual community according to its scientific body of knowledge. Secondly, the phenomenon of popular words, so-called "buzz words" used in this area obscures a clear differentiation between scientific terms and jargon [5]. The current study is based on the following working definition:

A virtual community consists of people who interact together socially on a technical platform. The community is built on a common interest, a common problem or a common task of its members that is pursued on the basis of implicit and explicit codes of behavior. The technical platform enables and supports the community's interaction and helps to build trust and a common feeling among the members.

\subsection{Dimensions to categorise virtual communities}

Similar to the diversity of definitions of the term virtual community, there exists a high diversity of dimensions used to categorise virtual communities ${ }^{2}$. Despite the large number of dimensions, researchers argue that many existing virtual communities cannot be categorised unambiguously. On the one hand, the reason for the difficulty in categorization may be due to the particular specification of the virtual community. For example, a

For an overview see also [10]. 
community for breast cancer patients with a regional focus can be classified as a geographic community, because of the regional focus, as a demographic community, because of the focus on women, and as a theme-centered community as the focus is issues related to breast cancer $^{3}$. Conversely, the difficulties encountered in attempting to categorise virtual communities might be caused by the fact that the existing categories are overlapping [12].

In order to keep the field of virtual communities used in this study as broad as possible and to be able to categorise virtual communities unambiguously, this study uses the financial interest of the operators of the community to categorise virtual communities. Therefore, in this study, commercial and non-commercial communities are distinguished.

\subsection{Success Factors}

Research on success factors generally focuses on the search for methods and models that explain success (of companies) and how to maximise it. Studies attempt to give recommendations - as detailed as possible - on how to provide and use resources in an ideal way. The recommendations are often insufficient as the number of influencing variables is high and the correlation between the variables is extremely diverse. Rather, research on success factors aims at formulating guidelines that can be influenced by the operators and that result in a strategy which is expected to be successful. [8]. Such orientation principles do not claim to fully explain all correlations, but try to give new ideas for the conception of approaches that might be more effective. In order to evaluate factors which contribute to the success of virtual communities, the study authors first summarize ${ }^{4}$ success factors of virtual communities as found in literature and subsequently evaluate them according to their importance for operators ${ }^{5}$ and members of virtual communities.

\subsection{Success factors of virtual communities}

A review of the literature revealed a great diversity of factors which influence the success of virtual communities. With regard to the evaluation of these factors, this study differentiates between member- and

These categories are taken from [11].

4 The extraction of success factors from literature is not covered in this paper, for more details on this see [13].

5 Some authors distinguish more stake-holders within a virtual community, especially when it comes to the organisation of a virtual community. Butler et al. [21] e.g. distinguish volunteers, equity holders and payroll employees and they state that each group has different motivations. Empirically identifying and addressing each of these groups is hardly possible in a brief survey. Therefore the authors desist from this differentiation for the purpose of this survey but acknowledge its role for continuative research. operator-oriented success factors. All together, 32 factors were identified: 26 were presented to members of virtual communities and all 32 to the operators (the six factors that are merely operator-oriented are highlighted gray in Table 1). The success factors have been reviewed, expanded and adjusted following the results of a Delphi study ${ }^{6}$ conducted among experts in the field of virtual communities. The Delphi study also tested potential correlations between the success factors. Table 1 gives an overview of the success factors. To be able to identify the success factors more easily, an identification number was assigned to each factor.

\begin{tabular}{|c|c|}
\hline Success Factors (in order of appearance in the questionnaire) & ID-\# \\
\hline Reaching a high number of members within a short period of time & 1 \\
\hline Building trust among the members & 2 \\
\hline Evolution of the community according to the ideas of its members & 3 \\
\hline Offering up-to-date content & 4 \\
\hline Offering high-quality content & 5 \\
\hline Appreciation of contributions of members by the operator & 6 \\
\hline Assistance for new members by experienced members & 7 \\
\hline $\begin{array}{l}\text { Establishing codes of behavior (netiquette/guidelines) to contain } \\
\text { conflict potential }\end{array}$ & 8 \\
\hline Supporting the community by regular real-world meetings & 9 \\
\hline Handling member data sensitively & 10 \\
\hline Arranging regular events & 11 \\
\hline Intuitive user guidance & 12 \\
\hline $\begin{array}{l}\text { Personalised page design of the community-site according to the } \\
\text { preferences of its members }\end{array}$ & 13 \\
\hline Establishing and supporting sub-groups within the community & 14 \\
\hline Integration of the members into the administration of the community & 15 \\
\hline Fast reaction time of the website & 16 \\
\hline Stability of the website & 17 \\
\hline Price efficiency of offered products and services & 18 \\
\hline Encouraging interaction between members & 19 \\
\hline Offering privileges or bonus programs to members & 20 \\
\hline Special treatment of loyal members & 21 \\
\hline Personalized product and service offers for members & 22 \\
\hline Focusing on one target group & 23 \\
\hline $\begin{array}{l}\text { Continuous community-controlling with regard to the frequency of } \\
\text { visits }\end{array}$ & 24 \\
\hline Continuous community-controlling with regard to member growth & 25 \\
\hline Continuous community-controlling with regard to member satisfaction & 26 \\
\hline $\begin{array}{l}\text { Defining sources of revenue as a starting condition for building a } \\
\text { virtual community }\end{array}$ & 27 \\
\hline Constant extension of offerings & 28 \\
\hline Building a strong trademark & 29 \\
\hline Existence of an off-line customer club as a starting advantage & 30 \\
\hline Increase of market transparency for community members & 31 \\
\hline $\begin{array}{l}\text { Sustaining neutrality when presenting and selecting offers to } \\
\text { community members }\end{array}$ & 32 \\
\hline
\end{tabular}

Table 1: List of success factors found in literature with assigned identification numers, operator-oriented success factors (presented only to the operators for evaluation) are highlighted in gray.

Cf. [13] Sidiras, P., Erfolgsfaktoren virtueller Gemeinschaften. Master Thesis at the Information Systems Department, Hohenheim University. 


\section{Research Method}

Design and procedure of the study are built on the model of designing empirical studies of Nieschlag/Dichtl/Hörschgen [14], a known and widely accepted model in the German social sciences. This model was adapted to the current problem and irrelevant intermediate steps were removed.

For the data collection, an overview of virtual communities by Bullinger et al. [7] was used. The communities listed in this overview were used as a starting point and a call for participation for the questionnaire was posted in all of the still existing communities. Similar to the snowball sampling method, links to other communities were spotted. The additional communities were added and calls for participation were posted on them as well. Altogether, messages were posted in 160 virtual communities covering a wide variety of online communities in respect to both size Table 1: Overview of the survey's key data

\begin{tabular}{|l|l|}
\hline $\begin{array}{l}\text { Department conducting the } \\
\text { investigation }\end{array}$ & $\begin{array}{l}\text { Information Systems } \\
\text { Department, Institute for } \\
\text { Business Administration, } \\
\text { Hohenheim University }\end{array}$ \\
\hline Timeframe & 07/24/2002- 08/19/2002 \\
\hline Method of data collection & Online-survey \\
\hline Universe & n. s. ${ }^{7}$ \\
\hline Number of persons surveyed & n. s. ${ }^{8}$ \\
\hline Sample & $\begin{array}{l}\text { members: } 644 \\
\text { (434 male and 210 female) } \\
\text { operators: 73 (34 commercial } \\
\text { and 39 non-commercial) }\end{array}$ \\
\hline
\end{tabular}

Table 2 gives a short overview of some of the general conditions of the survey.

An online-survey, a special type of written survey, was chosen for data collection. The literature provides several detailed guidelines on how to build on-line questionnaires. Three basic principles are included in all

7 No exact number, theoretically all members and operators of virtual communities worldwide.

8 Can only be defined approximately by the number of visits on the online-survey, approx. 3.500 visits

9 The communities covered in the study include:- Gaming-communities (e.g. Gamestar (online community of a German-speaking Computer-Game magazine), PlayersCommunity (www. playersconvention.de), etc.), -Customer Communities (e.g. BMW, Audi, Dell, Ebay, etc.), -Lifestyle-communities (e.g. metropolis.de (Germany's largest lifestyle-community with 1.5 mil. registered users), uboot.com, funworld.de, etc.), Computing-/Coding-Communities (e.g. PDA-Forum, scripts.org, phpcoders.de, etc.), -Sports-communities (soccer (borussiaforum.de), basketball (schoenen-dunk.de), etc.), -“exotic" special interest communities (e.g. Community of dog-owners (hundeforen-info), etc., to name just few. of these guidelines: Simplicity, neutrality and accuracy. Regarding the operationalisation of these principles see for example [15].

Online-surveys as a subtype of written surveys are a special way of collecting data. When positioning a questionnaire on the internet compared to sending it out via mail or hand to hand distribution, it can be stated that "only" the medium through which the questionnaire is presented has changed. Choosing an online survey as a method to collect data, poses some important consequences for the process of the investigation and for the design of the questionnaire. For further details see for example [16] and [17]. In summary, some basic problems occur when conducting an internet survey: The universe of internet users is basically undefined [18]; the sample is self selective and therefore cannot be regarded as being representative, statements about "nonparticipants" cannot be made [18].

The questionnaire used in this study was structured, tested and consequently adapted to the needs of the specific audiences targeted in this study. For this purpose a pretest followed by a discussion with the test persons was conducted. In addition, an online-pretest was carried out that tested the content and the functionality of the questionnaire.

The field phase generated a little more than 800 questionnaires for data analysis. After sorting out incomplete or inconsistent answers, 745 data sets were available for analysis. By dividing the questionnaire into several parts (at least 2) and due to different groups of interviewees (users and operators, male and female, commercial and non-commercial, etc.), several starting points for comparing groups with regard to their statements became apparent.

On this basis, rankings of success factors (according to the different groups) were established. The differences between their arithmetic means ${ }^{10}$ were tested and compared.

In addition questions referring to socio-demographic data as well as to internet usage and virtual community usage were analysed independently from the analysis of the success factors. The use of a bipolar verbal ordinal scale allowed members to express their agreement or disagreement with the statements (see figure 1).

\begin{tabular}{|c|c|c|c|c|}
\hline $\begin{array}{l}\text { Agree } \\
\text { strongly } \\
=1\end{array}$ & $\begin{array}{l}\text { Agree } \\
=2\end{array}$ & $\begin{array}{l}\text { undecided } \text { reject } \\
=3 \quad=4\end{array}$ & $\begin{array}{l}\text { reject } \\
\text { strongly } \\
=5\end{array}$ & $\begin{array}{l}\text { Not } \\
\text { specified } \\
=9\end{array}$ \\
\hline
\end{tabular}

Figure 1: Bipolar ordinal scale and re-interpretation into numbers.

10 A statictically significant deviation from the means can only be proven by a suited test procedure. In this case a two random sample test for the difference of two aritmetic means (cf. for example [19]), level of significance (here $\alpha=0.05$ ) was used. 
For data analysis the scale was reinterpreted into a numerical scale (shown in figure 2) (regarding the procedure see for example [20]).

For the analysis the data sets were divided into six groups: members (all), members (female), members (male), operators ${ }^{11}$ (all), operators (commercial), operators (non-commercial). In the following section these different groups will be compared with each other.

Table 2: Key data and answers of the survey among members (male: $n=434$, female: $n=210$ )

\section{Analysis of the Empirical Results}

First an overview of the characteristics of the respondents is given. This is followed by a description

\begin{tabular}{|l|l|l|}
\hline Survey among operators & $\begin{array}{l}\text { Commer } \\
\text { cial }\end{array}$ & $\begin{array}{l}\text { Non- } \\
\text { Commercial }\end{array}$ \\
\hline Period stayed in the internet (hours/day) & 7.28 & 6.13 \\
\hline Period stayed in the community (hours/day) & 3.46 & 2.68 \\
\hline Operators of ... communities & 1.82 & 1.26 \\
\hline Average time of operation (years) & 1.86 & 1.32 \\
\hline $\begin{array}{l}\text { Frequency of making statements in the community } 2.09 \\
\text { (1=more than once a day, } 5=n e v e r)\end{array}$ & 1.72 \\
\hline $\begin{array}{l}\text { Evaluation of the potential to make profit in the } 2.84 \\
\text { community } \\
\text { (1= very good, } 5=\text { very bad) }\end{array}$ & 2.97 \\
\hline $\begin{array}{l}\text { Satisfaction with the evolution of the community (1=very } 2.03 \\
\text { satisfied, } 5=\text { very unsatisfied) }\end{array}$ & 2.15 \\
\hline Share of operators who know members in real life (\%) & 73.5 & 76.3 \\
\hline
\end{tabular}

Table 3: Key data and answers of the survey among operators (commercial operators: $n=34$; non-commercial operators: $n=39$ ).

and comparison of the group of members with the group of operators.

\subsection{Generic statements of the respondents}

Table 3 shows the responses of the members of the virtual communities to the question regarding how long on average they stay on the internet during free- and work-time. About half of the time online is spent in the respective communities. Of note is that female respondents spend a large portion of their online-period in their communities as compared to their male counterparts. On average, respondents were members of three different communities, a concentration in only one community was not observed. The frequency of both writing and answering messages in the discussion forum was higher for men than for women. Seldom did either group order products or services via their virtual communities. A reason for this could be that the members are unsatisfied with the evolution of "their" community. This assumption was refuted by the survey: both men and women stated their satisfaction with the evolution of the communities they had joined.

11 The term operator is used for describing the party that operates (runs and manages) a virtual community.
On average, female respondents reported being members of a community for 1.42 years and men 2.02 years. However, female respondents reported more intensive personal (unmediated) contacts than male respondents. $65.1 \%$ of the women, as compared to $52.5 \%$ of the men, acknowledged having personally met at least one other member. Although there are no comparable values, both values seem to be relatively high, showing that on average every second respondent, irrespective of sex, knows at least one other community member personally. When interpreting this result it could be concluded that virtual communities play an important role in establishing personal relationships.

The group of operators (addressees are persons who operate a community, not institutions or companies) can be subdivided into the group of operators with commercial interest and the group of operators with no commercial interest. The survey of operators produced the following results (in addition see Table 4). As expected, the length of time the operators were online was much higher than the length of time spent online by members. Interestingly, commercial operators spent less than $50 \%$ of their daily online time in their own communities which cannot be explained by the fact that on average they operate 1.82 communities. Noncommercial operators run 1.26 communities on average. Asking operators for an evaluation of their potential profits / potential revenues there is no clear result as the average score of 2.9 corresponds with the answer category „uncertain“ - an answer given by both commercial and non-commercial operators.

As to reported satisfaction with the evolution of their community, on average both commercial and noncommercial operators indicated that they were

\begin{tabular}{|c|c|c|}
\hline Survey among members & Male & Female \\
\hline Period stayed in the internet (hours/day) & 5.01 & 4.6 \\
\hline Period stayed in the community (hours/day) & 2.27 & 2.2 \\
\hline Membership in ... communities & 2.98 & 2.79 \\
\hline Average time of membership (years) & 2.02 & 1.42 \\
\hline $\begin{array}{l}\text { Frequency of posting statements in the community } \\
(1=\text { more than once a day, } 5=\text { never) }\end{array}$ & 2.06 & 2.54 \\
\hline $\begin{array}{l}\text { Ordering commercial products via the community } \\
\text { (1=more than once a day, } 5=\text { never) }\end{array}$ & 4.62 & 4.63 \\
\hline $\begin{array}{l}\text { Satisfaction with the evolution of the community } \\
\text { (1=very satisfied, } 5=\text { very unsatisfied) }\end{array}$ & $y 2.27$ & 2.3 \\
\hline $\begin{array}{l}\text { Share of members who know other community } \\
\text { members in real life }(\%)\end{array}$ & $y 52.5$ & 65.1 \\
\hline
\end{tabular}

Table 4: Key data and answers of the survey among members (male: $\mathrm{n}=434$, female: $\mathrm{n}=210$ )

"satisfied" with the evolution of their community (2.03 for commercial and 2.15 for non-commercial operators). The reported reasons for satisfaction with evolution included the growing number of members and the interaction between the members of the community. The 
percent of commercial (73.5\%) and non-commercial (76.3\%) operators who reported personally knowing members seems relatively high. An explanation for this might be that operators get to know members in real life when trying to organise community meetings.

A comparison between the statements of the operators and the members and an analysis of the deviations between the two groups will be given in sections 4.2 and 4.3.

\subsection{Analysis of the success factors from the perspective of female and male members of virtual communities}

Table 5 shows the ranking of the importance of the individual success factors as they were perceived by all members. In addition, the table depicts how the success factors are ranked by male and female community members separately. In the last column of table 5 deviations between males and females are presented. The deviations that are significant are highlighted in yellow.

The ranking shows that in the perception of the members the handling of member data sensitively" is the most important factor contributing to the success of a virtual community. This is followed by more technical success factors such as stability and reaction time of the website. It is of interest to analyse which success factors were ranked differently by men and women. These differences are discussed in the following paragraphs.

Significant deviations (level of significance $\alpha>0.05$ ) between males and females and therefore different evaluations of the importance of specific success factors were measured in eight cases (see table 5, deviations are highlighted in red).

The success factor "supporting the community by regular real-world meetings" was evaluated as mediumimportant by both men and women although women (mean 2.69) rated it of slightly more importance than men (mean 2.91). This same situation exists e.g. in traditional self-help groups where female participants generally outnumber males. In contrast, the success factor "encouraging interaction between members" was evaluated to be more important to men than to women (mean of 1.99 compared to mean of 2.6). Therefore, although real-world contact between community members is less important to men than to women, men in this study seem to take virtual interaction more seriously than their female counterparts. This result supports the assumption that women have a higher inhibition threshold with regard to communication within the community than men ${ }^{12}$ whereas men attach

12 Which is supported by the fact that women post a lot less messages within the community than men, see 4.1 . less importance to the "real-world" advancement of the relationships built in the community than women do (as a supplement see table 4 in section 4.1).

These results could indicate that women might possibly use the community to make new contacts that can be intensified in the real world. Men, on the other hand, focus on the process of making new contacts but not necessarily intensifying them.

The highest deviation between male and female community members can be observed when comparing the ratings of the success factor "existence of an offline customer club as a starting advantage". Female community members ranked this success factor of significantly more importance than did males. Although this factor was ranked lowest by both groups, the higher rating given by women supports the previously discussed assumption that women desire off-line contact with other members.

Regarding the success factor "integration of the members into the administration of the community" , (involvement in tasks that only affect the virtual community and its administration), the picture changes again: Men clearly evaluate the importance of the participation in administrative tasks (and similar tasks like facilitating a forum) higher than women do (mean of 2.72 compared to mean of 2.94).

Summarising the previous paragraphs, it is noticeable that success factors regarding "off-line" communication and "off-line" interaction are evaluated to be more important to female respondents than to male respondents. Success factors relating to interaction within the community such as posting contributions and performing a task within the community were rated as being more important to male respondents than to female respondents. This insight is supported by answers to the overall questions such as the share of personal contacts that evolved from the community or the frequency of posting messages (see 4.1). It is also backed up by the analysis of answers to open questions asking for explanations for user satisfaction with the communities and for personal contacts emerging from the community. 


\begin{tabular}{|c|c|c|c|c|c|c|c|}
\hline $\begin{array}{l}\text { Overall } \\
\text { ranking }\end{array}$ & Success factors & Overall mean & $\begin{array}{l}\text { Mean } \\
\text { female }\end{array}$ & $\begin{array}{l}\text { Ranking } \\
\text { female }\end{array}$ & Mean male & Ranking male & $\begin{array}{l}\text { Deviation males vs. } \\
\text { females }\end{array}$ \\
\hline 1 & Handling member data sensitively & 1.34379906 & 1.2572816 & 1 & 1.3851508 & 1 & 0.12786921 \\
\hline 2 & Stability of the website & 1.44968553 & 1.4611651 & 2 & 1.4441861 & 2 & 0.01697905 \\
\hline 3 & Fast reaction time of the website & 1.59177215 & 1.4852941 & 3 & 1.6401869 & 3 & 0.15489282 \\
\hline 4 & Assistance for new members by experienced members & 1.77708006 & 1.75845411 & 5 & 1.7860465 & 4 & 0.02759240 \\
\hline 5 & $\begin{array}{l}\text { Establishing codes of behavior (netiquette/guidelines) to } \\
\text { contain conflict potential }\end{array}$ & 1.78144654 & 1.7378641 & 4 & 1.8023256 & 5 & 0.06446148 \\
\hline 6 & Offering up-to-date content & 1.8984127 & 1.87378641 & 6 & 1.9103774 & 7 & 0.03659095 \\
\hline 7 & Offering high-quality content & 1.90734824 & 1.99029126 & 7 & 1.8666667 & 6 & 0.12362459 \\
\hline 8 & Encouraging interaction between members & 2.04651163 & 2.16326531 & 10 & 1.9901478 & 8 & 0.17311753 \\
\hline 9 & $\begin{array}{l}\text { Evolution of the community according to the ideas of its } \\
\text { members }\end{array}$ & 2.06785137 & 2.02020202 & 8 & 2.0902613 & 9 & 0.07005926 \\
\hline 10 & Building trust among the members & 2.09191759 & 2.03883495 & 9 & 2.1176471 & 10 & 0.07881211 \\
\hline 11 & Sustaining neutrality when presenting and selecting offers & 2.25 & 2.25862069 & 11 & 2.2456647 & 12 & 0.01295595 \\
\hline 12 & Intuitive user guidance / usability & 2.25510204 & 2.31052632 & 12 & 2.2286432 & 11 & 0.08188310 \\
\hline 13 & Constant extension of offerings & 2.44041451 & 2.48677249 & 13 & 2.4179487 & 13 & 0.06882377 \\
\hline 14 & Price efficiency of offered products and services & 2.5390625 & 2.55813953 & 14 & 2.5294118 & 14 & 0.02872777 \\
\hline 15 & $\begin{array}{l}\text { Reaching a high number of members within a short } \\
\text { period of time }\end{array}$ & 2.738437 & 2.82673267 & 20 & 2.6964706 & 15 & 0.13026208 \\
\hline 16 & $\begin{array}{l}\text { Personalised page design of the community-site } \\
\text { according to the preferences of its members }\end{array}$ & 2.78093645 & 2.6751269 & 16 & 2.8329177 & 19 & 0.15779081 \\
\hline 17 & $\begin{array}{l}\text { Integration of the members into the administration of the } \\
\text { community }\end{array}$ & 2.79018613 & 2.94210526 & 22 & 2.7182045 & 16 & 0.22390077 \\
\hline 18 & Arranging regular events & 2.79581994 & 2.76699029 & 19 & 2.8100962 & 18 & 0.04310586 \\
\hline 19 & Increase of market transparency for community members & 2.80582524 & 2.66081871 & 15 & 2.877907 & 20 & 0.21708827 \\
\hline 20 & $\begin{array}{l}\text { Appreciation of contributions of the members by the } \\
\text { operators }\end{array}$ & 2.82954545 & 2.87755102 & 21 & 2,8071429 & 17 & 0,07040816 \\
\hline 21 & Supporting the community by regular real-world meetings & 2.8392283 & 2.69117647 & 17 & 2.9114833 & 21 & 0.22030678 \\
\hline 22 & Offering privileges or bonus programs to members & 2.87716263 & 2.75 & 18 & 2.9384615 & 22 & 0.18846154 \\
\hline 23 & $\begin{array}{l}\text { Establishing and supporting sub-groups within the } \\
\text { community }\end{array}$ & 2.99834711 & 3.00507614 & 23 & 2.995098 & 23 & 0.00997810 \\
\hline 24 & Special treatment of loyal members & 3.04269294 & 3.07179487 & 25 & 3.0289855 & 24 & 0.04280936 \\
\hline 25 & $\begin{array}{l}\text { Personalised product and service offers for community } \\
\text { members }\end{array}$ & 3.10694184 & 3.00568182 & 24 & 3.1568628 & 25 & 0.15118093 \\
\hline 26 & $\begin{array}{l}\text { Existence of an off-line customer club as a starting } \\
\text { advantage }\end{array}$ & 3.50190114 & 3.18128655 & 26 & 3.656338 & 26 & 0.47505148 \\
\hline
\end{tabular}

Table 5: Overall ranking and means of the success factors and breakdown of the results to males and females

Male and female members differ significantly in their evaluation of the success factor "Personalised page design of community-site", although it has to be stated that this difference is relatively small, just exceeding the threshold level of the testing procedure (mean of 2.83 for males compared to mean of 2.68 for females, which accounts for rank 19 for males and 16 for females). As both an average mean of 2.83 and an average mean of 2.68 can be interpreted as "undecided" scores, it can be assumed that the supposed efforts of many operators are not yet successful.

Regarding the more technically oriented success factors, there was greater agreement between the rankings of men and women. However, in response to the success factor "Fast reaction time of the website" male respondents reported more patience with regard to long waiting times within the community than women (mean of 1.64 for male respondents compared to mean of 1.48 for female respondents). Men rank this success factor third exceeded only by "stability of the website" and "handling member data sensitively". Women seem to be more demanding in terms of datedness and quality of published material. Although the ranking given to these factors by male respondents differs only slightly from the ranking by female respondents, the absolute values as evaluated by men are clearly below those of the female respondents. A similar difference in the reported level of importance is noted in the rating of the success factor "handling member data sensitively". In terms of absolute values, women rated the use of personal data as more important than did men (mean of 1.26 compared to mean of 1.39). Overall, however, the sensitive handling of personal data is ranked most important by both male and female respondents. 
4.3 Analysis of the success factors from the perspective of operators of virtual communities and comparison between statements made by operators of commercial and non-commercial virtual communities

The conducted analysis demonstrated no significant differences in responses between operators of commercial and non-commercial communities. In spite of the missing pre-conditions for the analysis of the success factors, the results will be presented in table 6 as some of the means are very close to the threshold level of the testing procedure.

The differences between the success factors with the ID\# 20 and \#25 are clearly apparent. Testing the differences on their significance, the threshold level is narrow.

However, the differences are clear enough that no statements valid at this significance level could be formulated.

Therefore, the expected confrontation between commercially and non-commercially oriented communities was not demonstrated by the study results at least not from the operator respondent groups. Although disagreement between the operators was not apparent, the study results demonstrate a wide range of disagreement between the commercially oriented operators and the members as a whole.

\begin{tabular}{|c|c|c|c|c|c|c|c|c|}
\hline ID-\# & Success factor & $\begin{array}{l}\text { Overall } \\
\text { ranking }\end{array}$ & Overall mean & $\begin{array}{l}\text { Mean } \\
\text { non-com. }\end{array}$ & $\begin{array}{l}\text { Ranking } \\
\text { non-com. }\end{array}$ & Mean commercial & $\begin{array}{l}\text { Ranking } \\
\text { commerci } \\
\text { al }\end{array}$ & $\begin{array}{l}\text { Deviation } \\
\text { non-com. vs. } \\
\text { commercial }\end{array}$ \\
\hline 10 & Handling member data sensitively & 1 & 1.328767123 & 1.33333333 & 1 & 1.32352941 & 1 & 0.00980392 \\
\hline 17 & Stability of the website & 2 & 1.534246575 & 1.51282051 & 2 & 1.55882353 & 2 & 0.04600302 \\
\hline 16 & Short reaction time of the website & 3 & 1.561643836 & 1.56410256 & 3 & 1.55882353 & 3 & 0.00527903 \\
\hline 4 & Offering up-to-date content & 4 & 1.638024076 & 1.69230769 & 5 & 1.57575758 & 4 & 0.11655012 \\
\hline 8 & $\begin{array}{l}\text { Establishing codes of behavior (netiquette/guidelines) to } \\
\text { contain conflict potential }\end{array}$ & 6 & 1.733914487 & 1.87179487 & 9 & 1.57575758 & 5 & 0.29603730 \\
\hline 3 & $\begin{array}{l}\text { Evolution of the community according to the ideas of its } \\
\text { members }\end{array}$ & 10 & 1.856164384 & 1.94871795 & 10 & 1.75000000 & 6 & 0.19871795 \\
\hline 26 & $\begin{array}{l}\text { Continuous community-controlling with regard to the } \\
\text { satisfaction of its members }\end{array}$ & 5 & 1.72384807 & 1.69444444 & 6 & 1.75757576 & 7 & 0.06313131 \\
\hline 7 & Assistance for new members by experienced members & 8 & 1.750103778 & 1.74358974 & 8 & 1.75757576 & 8 & 0.01398601 \\
\hline 19 & Encouraging interaction between members & 9 & 1.760612615 & 1.73684211 & 7 & 1.78787879 & 9 & 0.05103668 \\
\hline 12 & Intuitive user guidance / usability & 11 & 1.900878463 & 1.97297297 & 11 & 1.81818182 & 10 & 0.15479115 \\
\hline 5 & Offering high-quality content & 7 & 1.749143836 & 1.66666667 & 4 & 1.84375000 & 11 & 0.17708333 \\
\hline 2 & Building trust among members & 12 & 2.054794521 & 2.15384615 & 13 & 1.94117647 & 12 & 0.21266968 \\
\hline 32 & Sustaining neutrality when presenting and selecting offers & 15 & 2.219983884 & 2.41176471 & 17 & 2.00000000 & 13 & 0.41176471 \\
\hline 25 & $\begin{array}{l}\text { Continuous community-controlling with regard to growth } \\
\text { of the number of members }\end{array}$ & 14 & 2.166755619 & 2.28571429 & 14 & 2.03030303 & 14 & 0.25541126 \\
\hline 24 & $\begin{array}{l}\text { Continuous community-controlling with regard to the } \\
\text { frequency of visits }\end{array}$ & 16 & 2.251556663 & 2.44444444 & 19 & 2.03030303 & 15 & 0.41414141 \\
\hline 28 & Constant extension of offerings & 13 & 2.1327759 & 2.14285714 & 12 & 2.12121212 & 16 & 0.02164502 \\
\hline 29 & Building a strong trademark & 17 & 2.266915733 & 2.39393939 & 15 & 2.12121212 & 17 & 0.27272727 \\
\hline 18 & Price efficiency of offered products and services & 20 & 2.471200261 & 2.67857143 & 22 & 2.23333333 & 18 & 0.44523810 \\
\hline 22 & Personalised product and service offers for members & 22 & 2,550452544 & 2,78125000 & 24 & 2,28571429 & 19 & 0,49553571 \\
\hline 1 & High number of members within a short term & 18 & 2.347873107 & 2.39473684 & 16 & 2.29411765 & 20 & 0.10061920 \\
\hline 11 & Arranging regular events & 19 & 2.416355334 & 2.43589744 & 18 & 2.39393939 & 21 & 0.04195804 \\
\hline 9 & Supporting the community by regular real-world meetings & 23 & 2.563129492 & 2.68421053 & 23 & 2.42424242 & 22 & 0.25996810 \\
\hline 23 & Focusing on one target audience & 21 & 2.508509755 & 2.55555556 & 20 & 2.45454545 & 23 & 0.10101010 \\
\hline 6 & Appreciation of contributions of members by the operator & 25 & 2.743046907 & 2.88888889 & 26 & 2.57575758 & 24 & 0.31313131 \\
\hline 20 & Offering privileges or bonus programs to members & 28 & 2.876551168 & 3.11764706 & 30 & 2.60000000 & 25 & 0.51764706 \\
\hline 15 & $\begin{array}{l}\text { Integration of members into the administration of the } \\
\text { community }\end{array}$ & 24 & 2.648972603 & 2.61538462 & 21 & 2.68750000 & 26 & 0.07211538 \\
\hline 21 & Special treatment for loyal members & 29 & 2.880045452 & 3.02857143 & 29 & 2.70967742 & 27 & 0.31889401 \\
\hline 27 & $\begin{array}{l}\text { Defining sources of revenue as starting condition when } \\
\text { building a virtual community }\end{array}$ & 30 & 2.957685099 & 3.16129032 & 31 & 2.72413793 & 28 & 0.43715239 \\
\hline 13 & \begin{tabular}{|l|} 
Personalised page design of the community site \\
according to the preferences of its members
\end{tabular} & 26 & 2.774562496 & 2.81578947 & 25 & 2.72727273 & 29 & 0.08851675 \\
\hline 14 & \begin{tabular}{|l|l|}
$\begin{array}{l}\text { Establishing and supporting sub-groups within the } \\
\text { community }\end{array}$ \\
\end{tabular} & 27 & 2.873194818 & 2.89473684 & 27 & 2.84848485 & 30 & 0.04625199 \\
\hline 31 & Increasing market transparency for members & 31 & 3.041016981 & 2.96428571 & 28 & 3.12903226 & 31 & 0.16474654 \\
\hline 30 & $\begin{array}{l}\text { Existence of an offline customer club as starting } \\
\text { advantage }\end{array}$ & 32 & 3.540554955 & 3.29032258 & 32 & 3.82758621 & 32 & 0.53726363 \\
\hline
\end{tabular}

Table 6: Overall ranking and means of the success factors of the operators and breakdown of the results into commercial and noncommercial operators, arranged by the ranking of all statements by operators 


\section{4}

\section{Comparison between the Operators and the Members of Virtual Communities}

\subsubsection{Comparison between non-commercial operators of virtual communities and members}

Presuming that operators without commercial motivation deal with "their" community because of an intrinsic motivation, few differences between members of virtual communities and non-commercial operators should be expected (see also fig. 3).

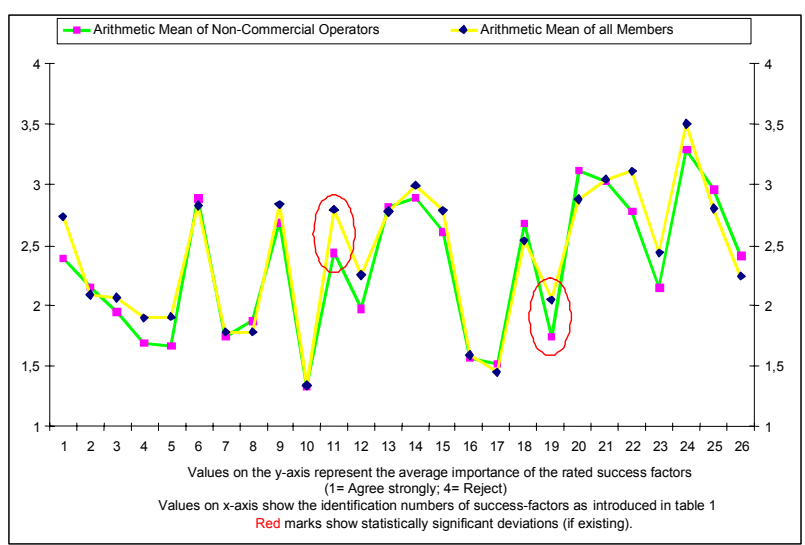

Figure 2: Evaluation of success factors by non-commercial operators and members

Supporting this assumption, only two success factors of significant difference could be identified

- ID-\# 11: Arranging regular events

- ID-\#19: Encouraging interaction between members

Taking into account that the success factor evaluated as least important by members accounts for a mean of 3.5, the average importance of 2.8 for "arranging regular events" seems to be relatively deflating. This result is even more surprising as the literature describes events as refreshing for community life and attractive to members [11]. Operators on average evaluate the importance of this success factor higher than members do (mean 2.44). Nevertheless the relatively low interest in events of community members of both genders remains surprising. Another unexpected result was the evaluation of the clearly community-oriented success factor "encouraging interaction between members", which was evaluated higher than the previously mentioned success factor (mean of 2.05 for members and a mean of 1.74 for operators). Overall the "population" of the community seems to prefer interacting without supporting influence from the outside.

The small number of differences between noncommercial operators and members demonstrated, to a large extent, that non-commercial operators and members were in agreement on factors that contribute to the success of virtual communities.

\subsubsection{Comparison between the statements of commercial operators of virtual communities and members}

Operators of commercially oriented communities are strongly dependent on the satisfaction and buying practices of their current and potential members for their success. In this light, the high number of significant deviations between members and commercial operators was especially surprising (to better visualise this result a frequency polygon was chosen, see figure 3 ). In the sample, operators and members identified somewhat different criteria as important for the community. The following success factors will be discussed in more detail:

- ID-\#1: Reaching a high number of members in a short peroid of time

- ID-\#3: Evolution of the community according to the ideas of the members

- ID-\#4: Offering of up-to-date content

- ID-\#9: Supporting the community by regular realworld meetings

- ID-\#11: Arranging regular events

- ID-\#12: Intuitive user guidance / usability

- ID-\#22: Personalised product and service offers for members

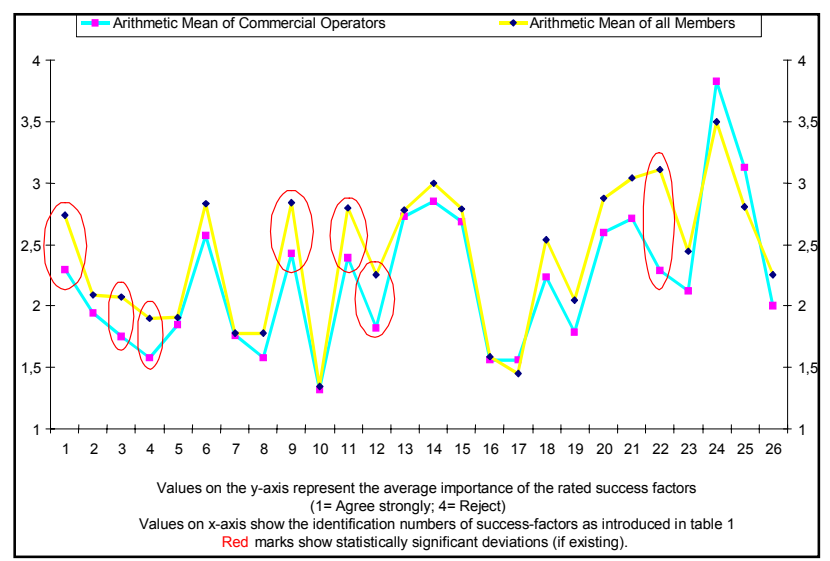

Figure 3: Evaluation of success factors by commercial operators and members

Although the success factor , reaching a high number of members within a short period of time" was ranked number 20 by commercial operators, an average importance of 2.29 was reported as compared to an average importance of 2.74 for members which 
coincides with rank 15 in their ranking list ${ }^{13}$. This result supports the assumption that reaching a large number of members within a short period of time is important to operators because of their dependency on day-to-day business. Even if not as much revenue is generated as may have been anticipated during the initial phases of a community, frequent visitors and a growing number of members are good predictors of future growth in revenue. In contrast, the members responding to this survey seem to prefer smaller-sized communities or at least, they do not see a high number of members as a pre-condition for their participation in a community. This is an unexpected result taking into account that respondents ranked "establishing and supporting subgroups within the community" on position 23 (of 26). If smaller group sizes are indeed preferred, this factor could be expected to be ranked higher.

When comparing both graphs in figure 3 , it can be stated that for each of the relevant deviations, the group of operators evaluated the success factor to be more important than the members did.

Most clearly this phenomenon occurs for the success factors "Intuitive user guidance / usability" and "Personalised product and service offers for members". In the case of "Personalised product and service offers for members" the threshold level of the test statistics is exceeded more than twice (mean of 2.29 for operators compared to mean of 3.11 for members).

In this study it can neither be conformed nor declined whether personalised offers influenced the community members. . As "Handling member data sensitively" was clearly ranked highest, the described result for "Personalised product and service offers for members" was not surprising. But, as operators survive by selling products or services no matter whether they have other sources of revenue or not, they evaluate them as highly important. It can be assumed that the participating members were mostly active in non-commercial communities and are therefore extremely critical towards commercialisation.

\subsubsection{Comparison between the statements of all operators and members}

After the detailed comparisons in the two previous sections, an additional comparison might seem to be unnecessary. However, because of the increased sample size (taking all operators into consideration) and the slightly changed variance of the statements, the testing procedure reveals one additional deviation:

- ID-\# 23: Constant extension of offerings.

13 It should be taken into account that 32 success factors were presented to the operators whereas only 26 were presented to the members of virtual communities.
The ,constant extension of offerings " was evaluated to be more important to community operators (mean=2.12) than to community members (mean=2.44). Operators consider the extension of their offerings as a natural evolution. By extending their offerings they distinguish themselves from other communities and attempt to open up new markets. Members did not consider this success factor as unattractive. However, this factor did not mean as much to them as for example "sustaining neutrality when presenting and selecting offers" (mean of 2.25).

\section{Conclusion and outlook for future research}

The following ten hypotheses for building and managing virtual communitites can be derived from the previously described results:

Hypothesis 1: The design of a technically performant platform with high stability and technical security is one of the most important success factors for a virtual community.

Hypothesis 2: A limitation to communication-/interaction-services is only promising for a short period of time. When aiming at sustainable success of a community, in addition to user-generated-content, high-quality and upto-date information should be provided.

Hypothesis 3: Handling member data / profiles sensitively is a vital success factor. Selling user data to third parties is counterproductive.

Hypothesis 4: The creation of personalised offerings is hardly ever promising.

Hypothesis 5: Community managers should both be able to react quickly to eventual problems and intervene in community life as little as possible.

Hypothesis 6: Although real-life events are important elements to increase interactivity in virtual communities, they are evaluated of lesser importantance to community members than to operators. Therefore, events should not be organised too often. It is more promising to limit this sort of activities to only a few events that are announced a long time in advance.

Hypothesis 7: Before changing lay-out or functionalities of a community site, it is important to give members the possibility to take part in the modification of design/functionality or the extension of the offerings first.

Hypothesis 8: Male community members are motivated to take part in a virtual community by the possibility to easily make new contacts without commitment. They do not wish to transfer these contacts into real-life. Most often they make new contacts because they look for information. Building up social capital is more important to male community members than to females.

Hypothesis 9: Female community members are often motivated to take part in a virtual community in order to carry on existing contacts without limits of time and place or in order to extend new "online" contacts into real-life. They are more interested in social interaction than men and less interested in building up social capital (e.g. by performing tasks in the community or by frequently posting messages).

Hypothesis 10: It is more important to operators of virtual communities to sustain neutrality than to constantly extend their offerings for community members.

Most importantly, this study revealed that both operators and members of virtual communities clearly focus on performance, security, and up-to-datedness and quality of the content. In this study ,typical“ success factors of virtual communities, as found in the literature, were rated rather low. The respondents were not focused on the existence of sub-groups, special treatments, 
privileges or regular meetings, but rather on the performance of the internet presence from both a technical and a content point of view. The success factor ranked to be the most important by all respondents was "handling member data sensitively". This result highlights the significance of data security (even for non-commercial communities) and the need for managers and operators of virtual communities to be attentive to this issue to foster success of their site.

Recapitulating, the following can be stated: As this study followed an explorative research design, the results should be researched in more detail. In spite of the restrictions of the current study (e.g. the missing representativeness of the sample and the methodological restrictions of an online survey) the ten hypotheses derived from this study should be verified in a larger study using more detailed and sophisticated empirical instruments. A follow-up study should also analyse the hypotheses in more detail by using a more detailed categorisation of virtual communities or by defining member sub-groups in more detail.

\section{References}

[1] Rheingold, H., The Virtual Community Homesteading on the Electronic Frontier. 1993, Reading, MA: Addison Wesley.

[2] Armstrong, A. and J. Hagel III, Real Profits from Virtual Communities. The McKinsey Quarterly, 1995(3): p. 128-141.

[3] Armstrong, A. and J. Hagel III, The Real Value of Online Communities. Harvard Business Review, 1996. 74(3): p. 134- 41.

[4] Kim, A.J., Secret Strategies for Successful Online Communities / Community-Building On The Web. 1999, Berkeley: Peachpit Press.

[5] Preece, J., Online Communities - Designing Usability, Supporting Sociability. 2000, Chichester, New York, Weinheim, Brisbane, Singapore, Tokio: John Wiley and Sons. 439.

[6] Brunold, J., H. Merz, and J. Wagner, www.cybercommunities.de: Virtual Communities: Strategie, Umsetzung, Erfolgsfaktoren. 2000, Landsberg/Lech: mi, Verlag Moderne Industrie. 257.

[7] Bullinger, H.-J., et al., Business Communities. 2002, Bonn: Galileo.

[8] Tromsdorf, V., Erfolgsfaktorenforschung, Produktinnovation und Schnittstelle Marketing-F\&E. Diskussionspapier/Technische Universität Berlin, Wirtschaftswissenschaftliche Dokumentation. 1990, Berlin: Technische Universität Berlin.

[9] Schoberth, T. and G. Schrott, Virtual Communities. Wirtschaftsinformatik, 2001. 43(5): p. 517-519.

[10] Leimeister, J.M., P. Sidiras, and H. Krcmar. Erfolgsfaktoren virtueller Gemeinschaften aus Sicht von Mitgliedern und Betreibern - Eine empirische Untersuchung. in 6. Internationale Tagung
Wirtschaftsinformatik 2003-Medien - Märkte Mobilität. 2003. Dresden.

[11] Hagel III, J. and A. Armstrong, Net Gain Expanding markets through virtual communities. 1997, Wiesbaden: Gabler Verlag.

[12] Brunold, J., H. Merz, and J. Wagner, www.cybercommunities.de - Virtual Communities: Strategie, Umsetzung, Erfolgsfaktoren. 2000, Landsberg/Lech: mi, Verlag Moderne Industrie. 257.

[13] Sidiras, P., Erfolgsfaktoren virtueller Gemeinschaften: Eine Analyse und Gegenüberstellung empirischer Untersuchungen, Master Thesis at the Information Systems Department, Hohenheim University.

[14] Nieschlag, R., E. Dichtl, and H. Hörschgen, Marketing. 19., überarbeitete und ergänzte Auflage ed. 2002, Berlin: Duncker\&Humboldt.

[15]Büning, H., et al., Operationale Verfahren der Markt- und Sozialforschung - Datenerhebung und Datenanalyse. 1981, Berlin: Walter de Gruyter GmbH\&Co.KG.

[16] Gadeib, A., Ansprüche und Entwicklung eines Systems zur Befragung über das World Wide Web., in Online Research - Methoden, Anwendungen und Ergebnisse, W. Bandilla, B. Bantinic, and L. Gräf, Editors. 1999, Verlag für Psychologie Dr. C.J. Hogrefe: Göttingen. p. 103-111.

[17] Bantinic, B., K. Moser, and B. Puhle, Der $W W W$ Fragebogengenerator, in Online Research Methoden, Anwendungen und Ergebnisse, W. Bandilla, B. Bantinic, and L. Gräf, Editors. 1999, Verlag für Psychologie Dr. C.J. Hogrefe: Göttingen. p. 93-102.

[18]Hauptmanns, P., Grenzen und Chancen von quantitativen Befragungen mit Hilfe des Internet., in Online Research - Methoden, Anwendungen und Ergebnisse, W. Bandilla, B. Bantinic, and L. Gräf, Editors. 1999, Verlag für Psychologie Dr. C.J. Hogrefe: Göttingen. p. 21-38.

[19] Voß, W., Taschenbuch der Statistik. 1 ed. 2000, München: Carl Hanser Verlag.

[20]Fahrmeir, L., et al., Statistik - Der Weg zur Datenanalyse. 2 ed. 1999, Berlin, Heidelberg: Springer.

[21]Butler, B., et al., Community effort in online groups: who does the work and why?, in Leadership at a distance, S. Weisband and L. Atwater, Editors. 2003, Erlbaum. 